\title{
Finite Element Simulation \& Optimization of Steering Gear Sector Shaft Fixture Plate
}

\author{
Amol Bhanage ${ }^{\# 1}$, Rupesh Sundge ${ }^{* 2}$, Abhishek Chavan ${ }^{\# 3}$ \\ ${ }^{\# 1}$ Assistant Professor, Mechanical Department, Marathwada Mitra Mandal's Institute of Technology, \\ Pune University, Pune, Maharashtra, India \\ 1 amol.bhanage@yahoo.com \\ ${ }^{* 2}$ Assistant Professor, Mechanical Department, KJ College of Engineering \& Management Research, \\ Pune University, Pune, Maharashtra, India \\ ${ }^{2}$ rupesh.sundge@gmail.com

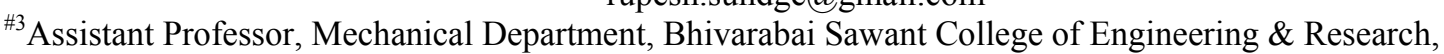 \\ Pune University, Pune, Maharashtra, India \\ ${ }^{3}$ chavanabhishek73@gmail.com
}

\begin{abstract}
The sector shaft serves as the output shaft of the steering gear and it, converts the longitudinal motion of the piston to rotary motion of the output end of the sector shaft. Distortion in sector shaft can causes shaft incapable of serving its intended function. Permanent distortion can cause failure. It's may affect many parameters like uneven heat treatment, geometry design, fixture geometry consideration etc. Current value is $\mathbf{8 0}$ to 180 micron. In the present work, the distortion of steering gear sector shaft minimized by optimization design on fixture plate for proper assembly and some trials taken on new fixture plate design for validation. Design optimization of a sector shaft fixture plate is done using ANSYS Workbench Simulation.
\end{abstract}

Keywords- ANSYS, Distortion, Fixture Plate, Sector Shaft

\section{INTRODUCTION}

The sector shaft as shown in Fig. 1 is a critical component of an automotive power assisted steering gear. The Sector shaft serve as the output shaft of the steering gear and is so-called because it contains a sector gear in mesh with a gear portion of a hydraulic piston contained within the gear housing. The sector gear converts the longitudinal motion of the piston into rotary motion of the output end of the sector shaft.

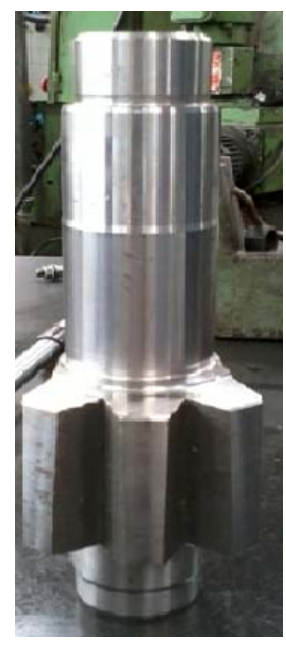

Fig.1. Sector Shaft

The sector shaft is critical component of an automotive power assisted recirculating ball steering gear and one that is vulnerable to fracture due to loads transmitted through the steering linkage under certain conditions [1]. There are various variables that influences distortion such as material chemistry, harden ability, part geometry and design consideration [2]. Distortion is a general term that involves all irreversible dimensional change produced during heat-treatment operations. This can be classified into two categories: size distortion, which is the net change in specific volume between the parent and transformation product produced by phase transformation without a change in geometrical form, and shape distortion or warpage, which is a change in geometrical form or shape and is revealed by changes of curvature or curving, bending, twisting, and/or nonsymmetrical dimensional change without any volume change [4]. 
Currently, Sector shaft Distortion value is 80 to 180 micron. It is always advisable to minimize distortion in sector shaft and minimize the problem in future due to distortion effect. Distortion is sector shaft occurs due to heat treatment. So need to design new fixture model which will properly support the components. This paper mainly included the design and simulation of Fixture.

\section{Optimization Process}

Sector shaft distortion value before optimization due to heat treatment is about up to 180 micron. Start with force analysis, new fixture is designed with hexagonal shape. Material is selected as heat resistant alloy castings with tensile strength of $700 \mathrm{~N} / \mathrm{mm}^{2}$. Hexagonal shape tray is design by considering of direct shear load, bending load and on thermal stresses. Finite element simulation will find out von - mises stress, principal stress and shear stress for prediction of safety factor of new fixture tray. Trial is taken at last for prediction of variation of distortion and help for confirmation of result validation.

\section{Force Analysis Calculation}

The fixture comprises of five job holder trays with the arrangement of components. For Simplicity, consider individual tray for design and simulation as shown in Fig. 2.

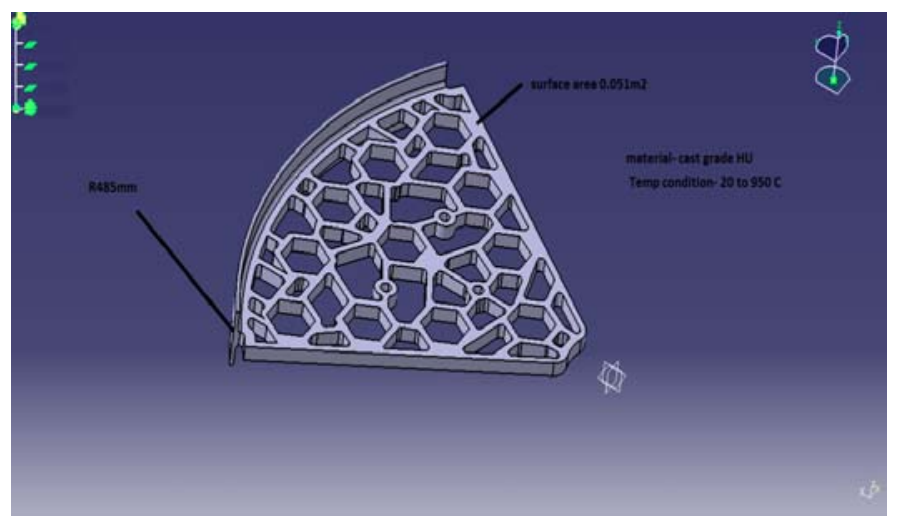

Fig.2. Five Job Holder Fixture Plate (Individual Plate)

In new fixture design, as shown in Fig. 3, a gap of $2 \mathrm{~mm}$ (Hexagonal slot across flat is $52 \mathrm{~mm}$ for locating 50 $\mathrm{mm}$ diameter gear sector boss) is maintained to account for thermal expansion and minimal misalignment while placing the work-piece in fixture.

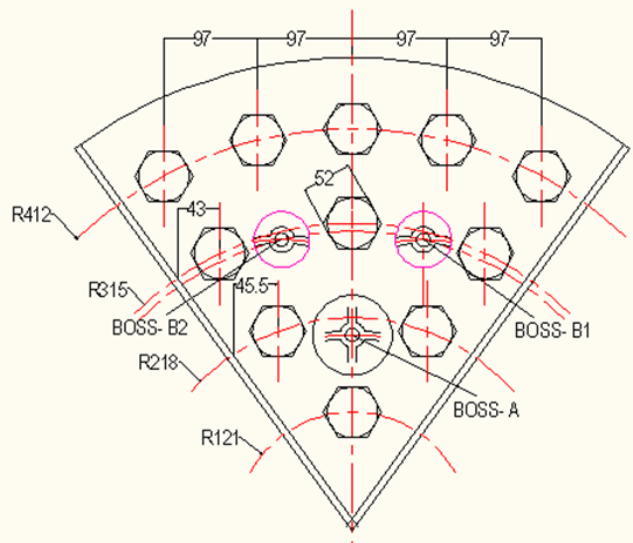

Fig.3. Fixture Plate Layout

\section{A. Dead weight forces on each tray}

Dead weight forces on each tray = Summation of masses of work-pieces in each tray (11 no's)

$\mathrm{W}($ tray) $=491 \mathrm{~N}$

Dead weight of holder system (neglecting tray weight)

$\mathrm{W}($ holder $)=\mathrm{W}($ tray $) \times 5=2454 \mathrm{~N}$

Bending moments resulting due to work-piece in one tray

$\mathrm{M}=92.016 \mathrm{~N}-\mathrm{m}$ 


\section{B. Selection of material for tray and holder}

Heat resistant alloy castings

Alloy casting institute designation: $\mathrm{HU}$

Alloy type: $39 \mathrm{Ni}-18 \mathrm{Cr}$

$\mathrm{HU}$ is an austenitic NI-Fe-Cr alloy with moderate creep-rupture strength and good ductility. Oxidation and carburization resistance rank highly. These properties combine to give a good resistance to thermal fatigue and shock that is particularly suited for furnace components in long term service at low stresses, at temperatures up to $2100^{\circ} \mathrm{F}$. As cast condition, the tensile strength is $700 \mathrm{~N} / \mathrm{mm}^{2}$.

TABLE I. Material Constituents

\begin{tabular}{|c|c|}
\hline Constituents & Contents \\
\hline $\mathrm{Ni}$ & $37-41$ \\
\hline $\mathrm{Cr}$ & $17-21$ \\
\hline $\mathrm{C}$ & 0.7 \\
\hline $\mathrm{Mn}$ & 2 \\
\hline $\mathrm{Si}$ & 2.5 \\
\hline $\mathrm{Mo}$ & 0.5 \\
\hline
\end{tabular}

C. Design of tray section at job holder point for direct shear load due to individual work-piece

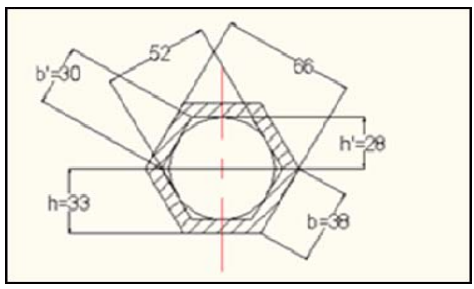

Fig.4. Area subjected local Direct Shear

$\left(\tau_{\text {act }}\right)=44.635 / 1242=0.03<700 \mathrm{~N} / \mathrm{mm}^{2}$

1) Design of tray section at Boss-A for direct shear load due to net dead weight Weight shared by each boss $=$ Net load $3=163.66 \mathrm{~N}$

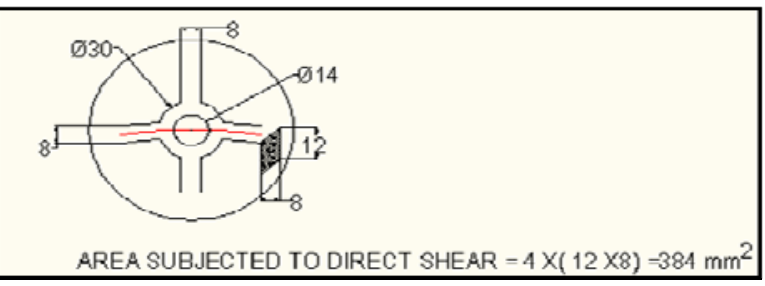

Fig.5. Boss A (Area subjected to Direct Shear)

$$
\left(\tau_{\text {act }}\right)=163.66 / 384=0.426 \mathrm{~N} / \mathrm{mm}^{2}
$$

2) Design of tray section at Boss-B1 for direct shear load due to net dead weight

Weight shared by each boss $=$ Net load $/ 3=163.66 \mathrm{~N}$

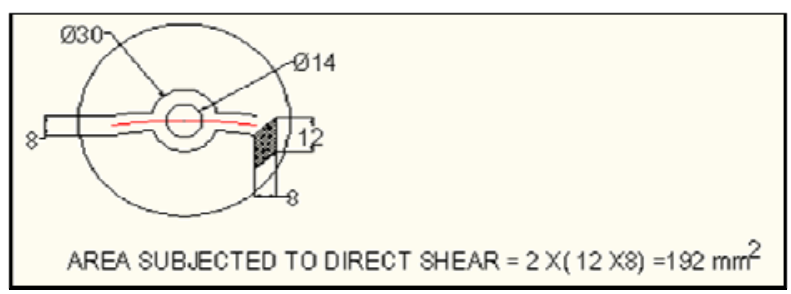

Fig.6. Boss B1 (Area subjected to Direct shear)

$\left(\tau_{\text {act }}\right)=163.66 / 192=0.85 \mathrm{~N} / \mathrm{mm}^{2}$ 
3) Design of tray section at Boss-B2 for direct shear load due to net dead weight Weight shared by each boss $=$ Net load $/ 3=163.66 \mathrm{~N}$

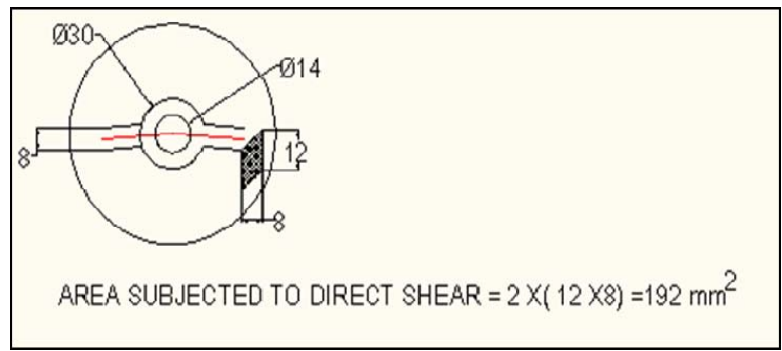

Fig.7. Boss B2 (Area Subjected under Direct Shear)

$\left(\tau_{\text {act }}\right)=163.66 / 192=0.85 \mathrm{~N} / \mathrm{mm}^{2}$

It concluded that, Tray is safe in direct shear stress under action of dead weight of each component.

D. Design of Holder Hub

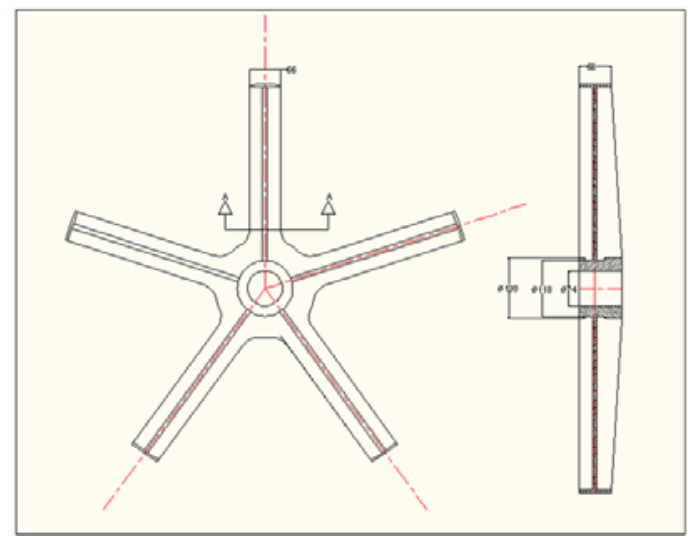

Fig.8. Holder Hub

1) Design of hub section under direct shear load resulting due to weight of the trays with work-piece

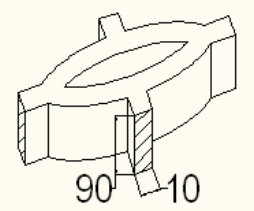

Tray is safe in direct shear stress under action of dead weight of each component.

2) Design of hub section under bending load resulting due to weight of the trays with work-piece $\mathrm{F}_{\mathrm{b}}=$ (total moment) / Total section modulus

$$
=92016 \times 6 / 5 \times\left(10 \times 66^{2}+90 \times 10^{2}\right)=2.1 \mathrm{~N} / \mathrm{mm}^{2}
$$

As $\mathrm{Fs}_{\text {act }}<\mathrm{Fs}_{\text {allowable }}$

Tray is safe in bending under action of dead weight of each component.

3) Design of the holder shaft under direct Compressive load due to weight of the holder with trays and workpiece

\begin{tabular}{|c|c|}
\hline Designation & C40 \\
\hline Tensile Strength, N/mm & 680 \\
\hline Yield strength, N/mm & 380 \\
\hline
\end{tabular}




\section{Geometry Of Plates}

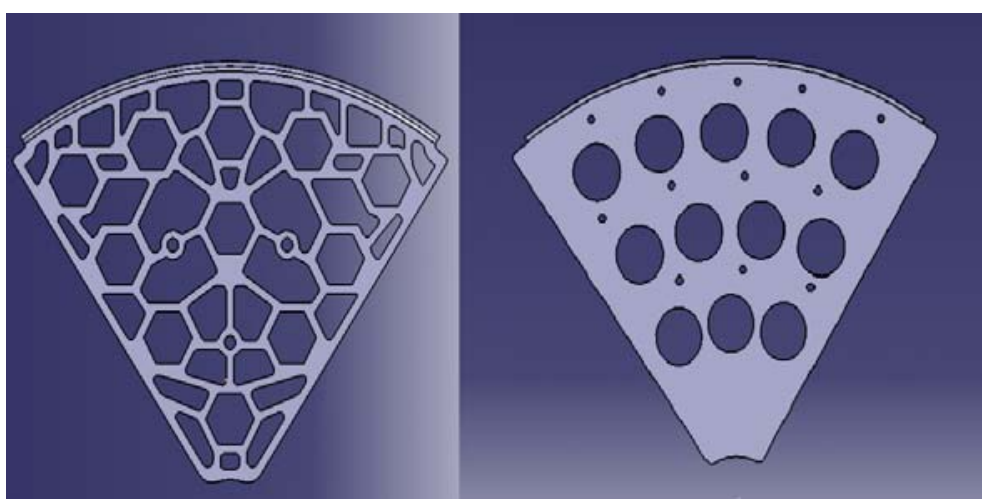

Fig.9. (a) New Optimized Fixture Plate (b) Old Fixture Plate

\section{A. Shape consideration}

1. Hexagonal shape is taken instead of circular to reduce no. of point of contact

2. Bosses are provided to increase the strength of the plate.

3. Material is removed to reduce material.

4. Uniform width of $9 \mathrm{~mm}$ is maintained uniformly by removing material

\section{Finite ELEMENT MODELling}

\section{A. Boundary Conditions}

Fig. 10 (a) \& (b) and Fig. 11 (a) \& (b) shows boundary condition applied for optimized new and old fixture plate. Mesh size of $3 \mathrm{~mm}$ and load of $44.64 \mathrm{~N}$ is applied for both plates for finite simulation purpose shown in Fig. 12 (a) \& Fig. 12 (b).

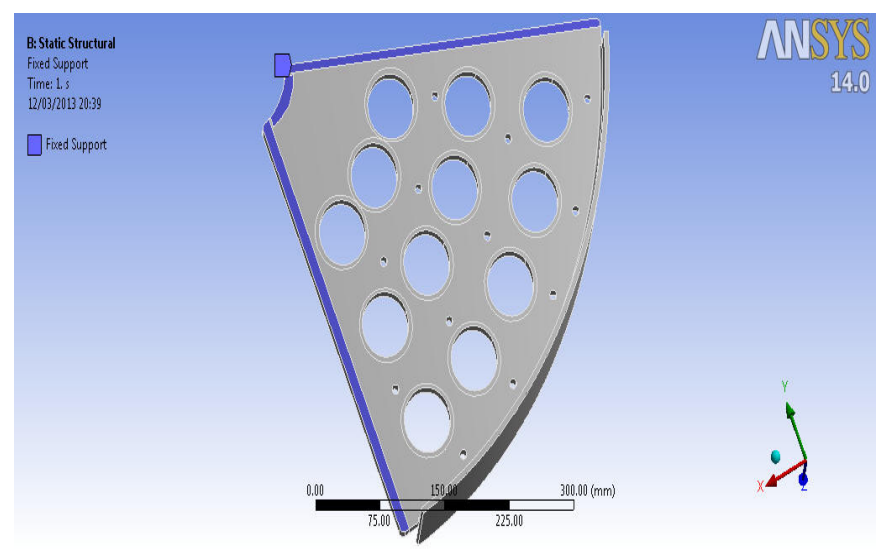

Fig. 10 (a) Old Fixture Plate (Boundary Condition)

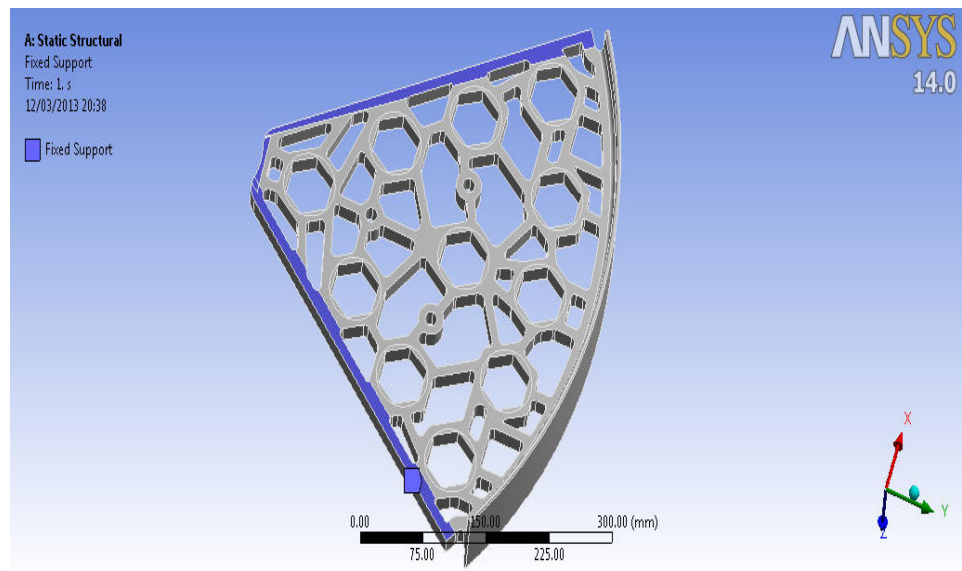

Fig.10 (b) New Fixture Plate (Boundary Condition) 


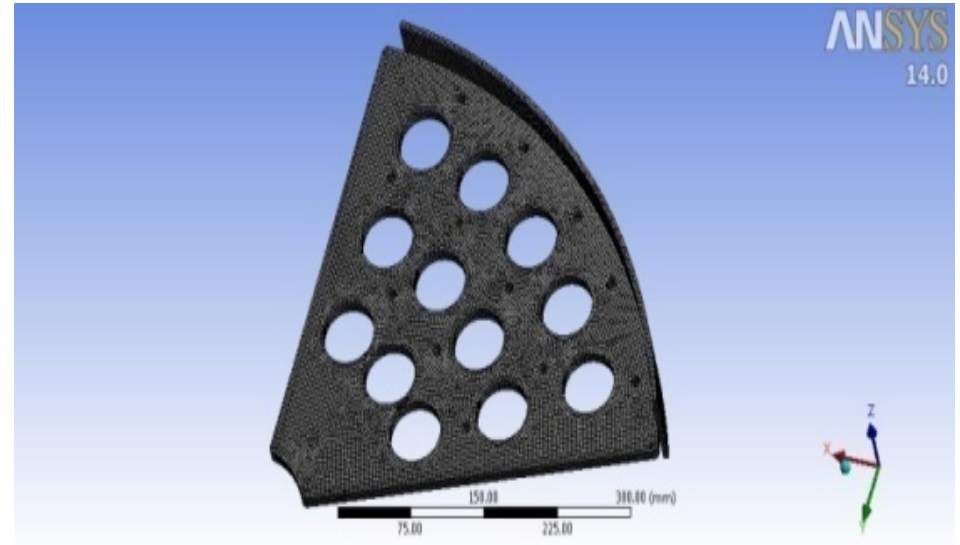

Fig.11 (a) Old Fixture Plate (Meshing)

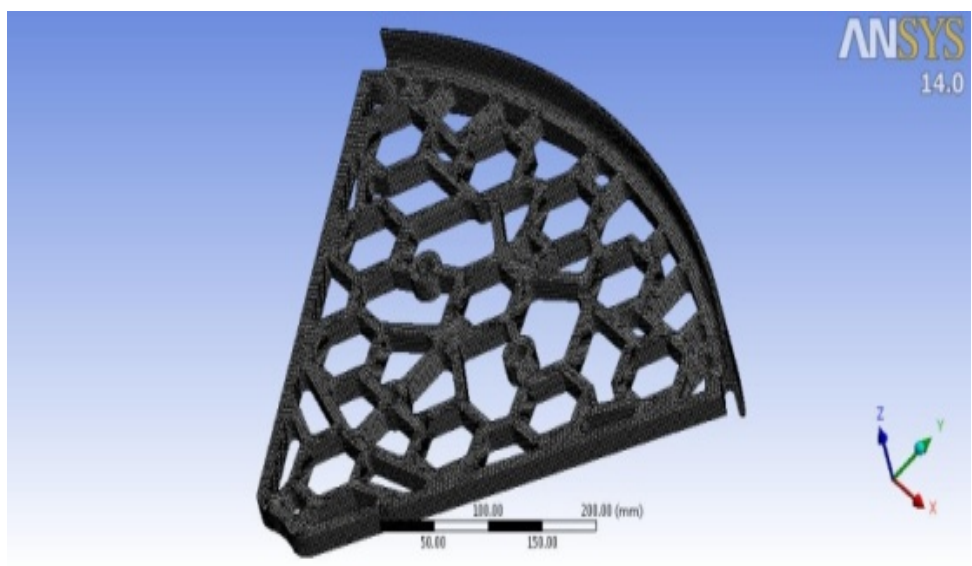

Fig.11 (b) New Fixture Plate (Meshing)

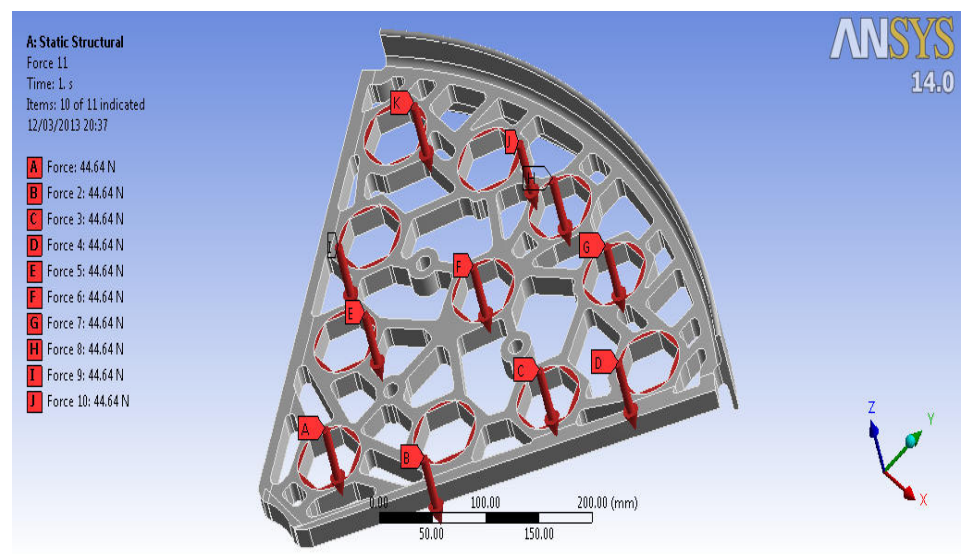

Fig. 12 (a) New Fixture Plate (Loading) 


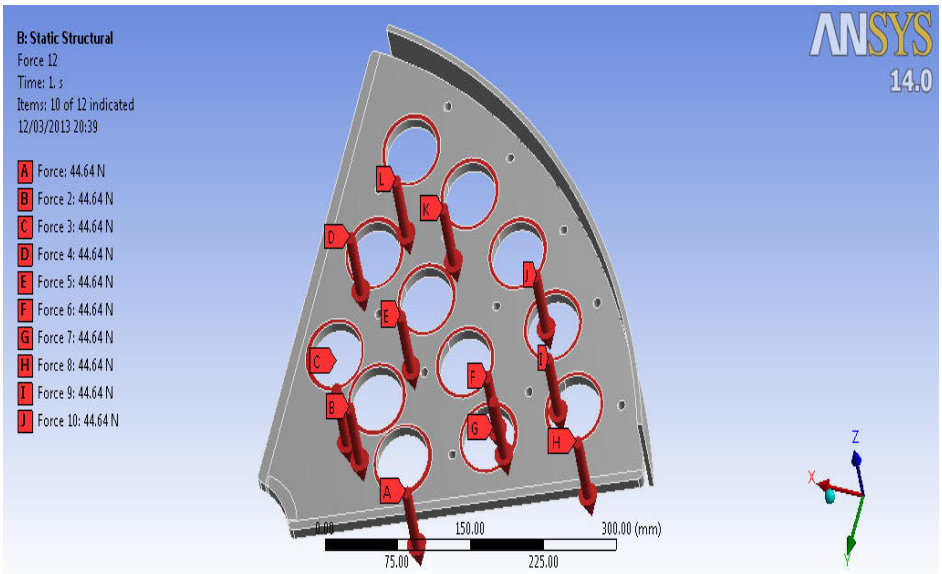

Fig. 12 (b) Old Fixture Plate (Loading)

\section{RESUlts AND Discussion}

\section{A. Simulation Results}

Fig. 13 shows Shear stress distribution and deformation of optimized new and previous old fixture plate. Optimized Plate shows Von Mises Stress and Principal stress of 3.67 MPa and 1.70 MPa respectively. The deformation and related stress parameter are calculated and differences mentioned in Table II for optimized and old fixture plate.

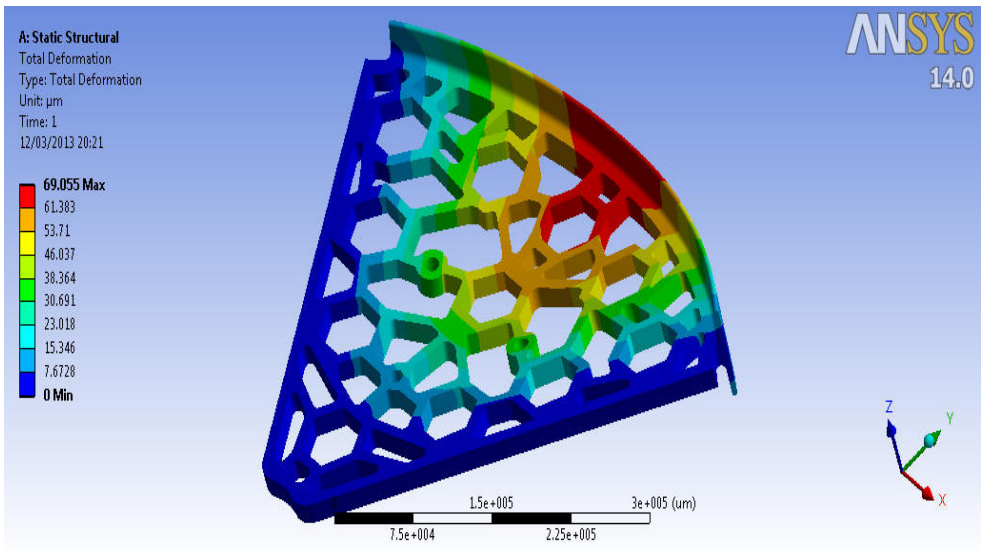

Fig. 13 (a) Shear Stress distribution for new Plate

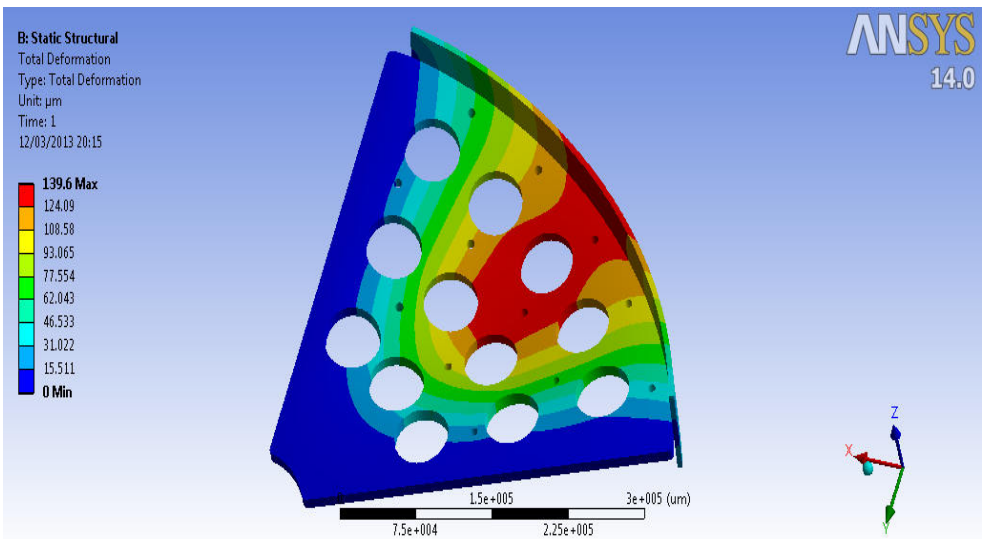

Fig. 13 (b) Shear Stress distribution for old Plate 


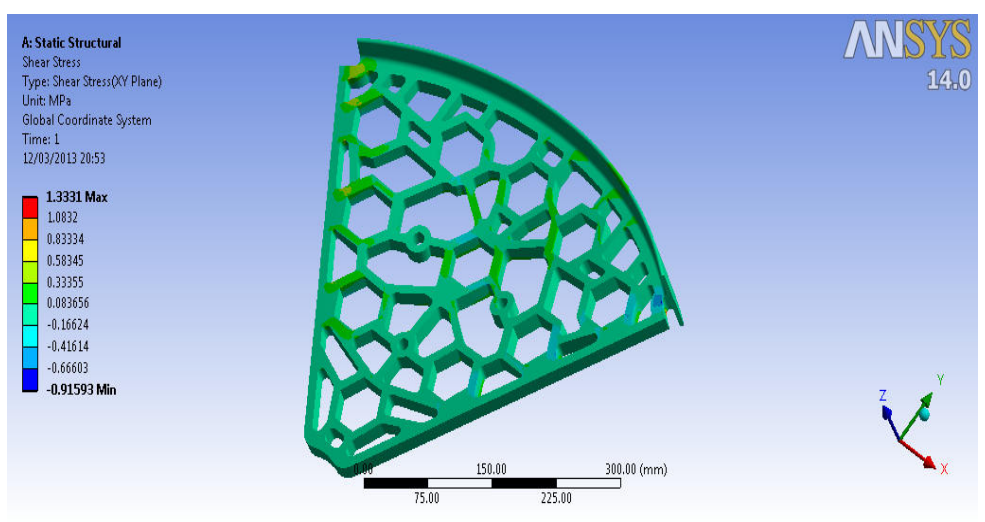

Fig. 13 (c) Deformation in new fixture plate

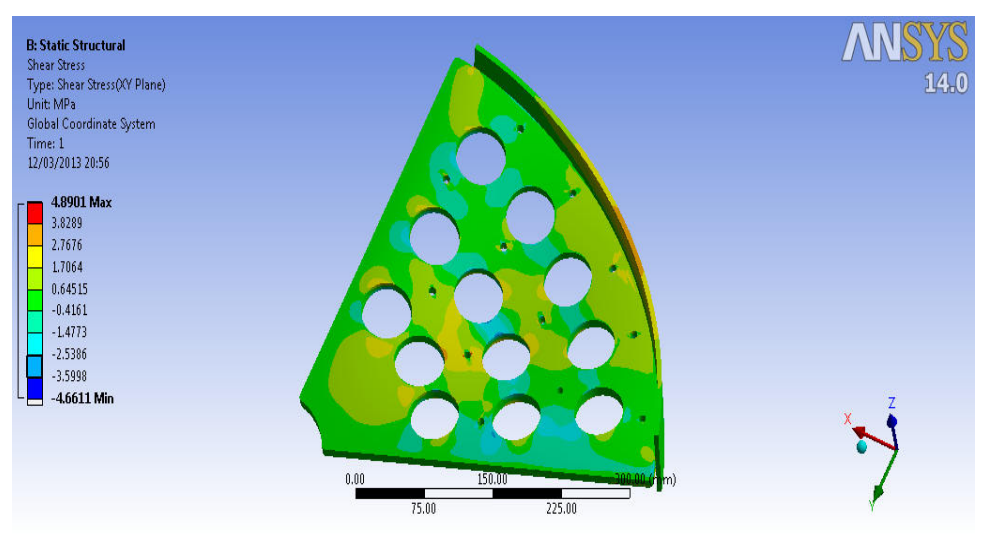

Fig. 13 (d) Deformation in old fixture plate

TABLE III. Simulation Results

\begin{tabular}{|l|c|c|}
\hline Parameter & New Fixture Plate & Old Fixture Plate \\
\hline Nodes & 314616 & 249686 \\
\hline Elements & 74470 & 61584 \\
\hline Shear stress, MPa & 1.33 & 4.89 \\
\hline Von Mises Stress, MPa & 3.67 & 18.63 \\
\hline Principal Stress, MPa & 1.70 & 18.55 \\
\hline Normal Stress, MPa & 1.55 & 10.025 \\
\hline Deformation, $\mathrm{mm}$ & 69.05 & 139.6 \\
\hline
\end{tabular}

\section{B. Variation in Heat Treatment for Sector shaft CD, run out - Trial batch}

After taken trial on new fixture design plate, distortion is reduced by 50-60 micron which is large change so $50 \%$ rework is reduced due to this solution. Fig. 14 shows variation of distortion in microns for both plates where, new optimized plate shows reduction in distortion. 


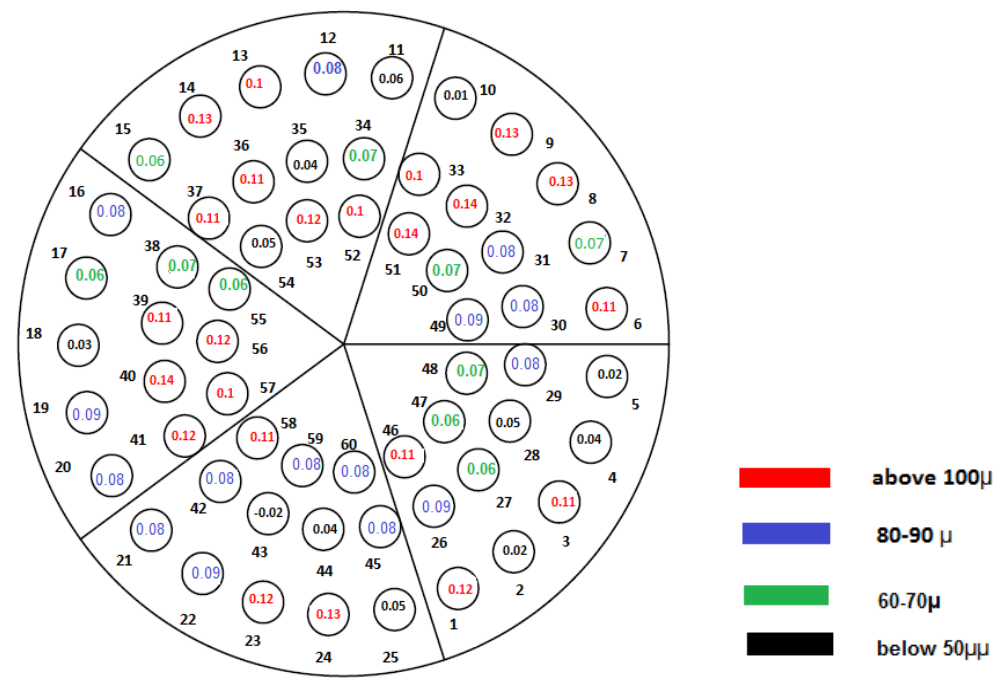

Fig.14 (a) Old fixture plate Trial Reading

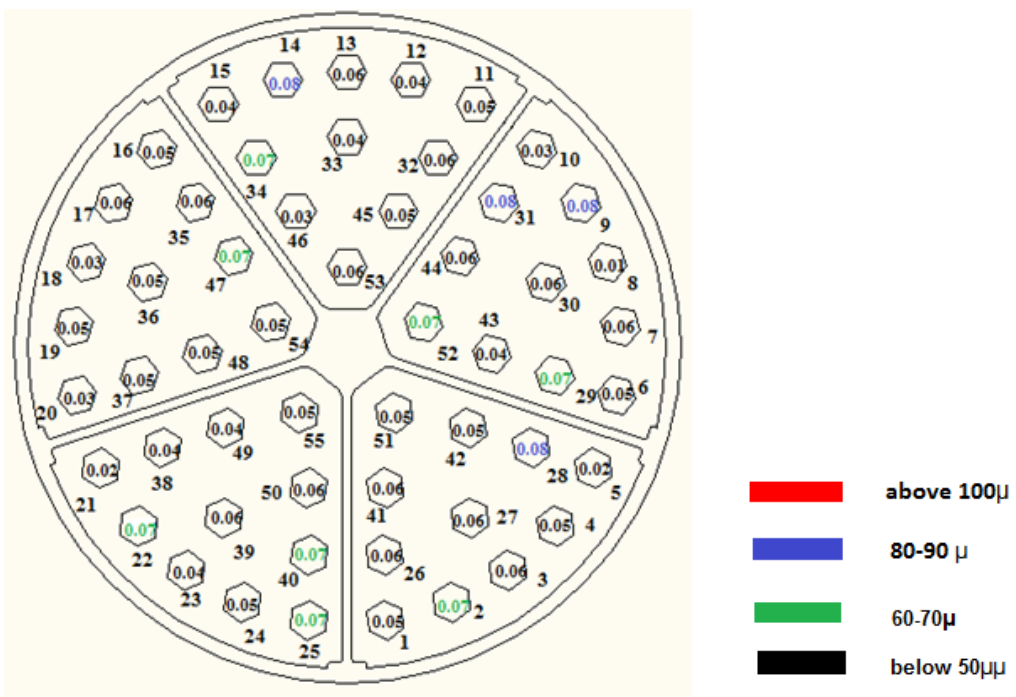

Fig. 14 (b) New fixture plate Trial Reading

\section{CONCLUSION}

Here, in our design distortion primarily affected due to design of fixture plate. Detail force analysis design is done on five job holder fixture plate. Shape optimization is done from circular to hexagonal shape for strength and weight parameters point of view. Finite element simulation shows von-mises $3.67 \mathrm{MPa}$ and principal stress of $1.70 \mathrm{MPa}$ of optimized plate, which is comparatively less than old fixture plate. Design optimization study predicted minimization in distortion in sector shaft from 80 to 180 micron to 50- 60 micron done on fixture plate for proper support to components using design calculation and ANSYS Workbench Simulation software, which reduced $50 \%$ of rework.

\section{REFERENCES}

[1] J. D. Varin, "Fracture Characteristics of Steering Gear Sector Shafts," Practical Failure Analysis, ASM International, vol.2 (4), pp. 6569, 2002.

[2] Daniel H. Herring \& Gerald D. Lindell, "Reducing Distortion in Heat-Treated Gears," Gear solution, pp. 27-35, 2004

[3] Dr. Kirpal Singh, "Automobile Engineering vol. 1", D; Standard Publishers Distributors; 12th Edition. pp. 230-240, 2011

[4] Anil Kumar Sinha, Bohn Piston Division, "Defects and Distortion in Heat-Treated Parts," ASM Handbook, vol.4: Heat Treating ASM Handbook Committee, pp. 601-619, 1991 